ISSN: 1130-3743 - e-ISSN: 2386-5660

DOI: http://dx.doi.org/10.14201/teoredu2016281159188

\title{
LA RESPONSABILIDAD SOCIAL EN LA UNIVERSIDAD ESPAÑOLA
}

\author{
University's social responsibility at Spanish universities
}

\section{Responsabilité sociale dans l'université espagnole}

\author{
Marta Ruiz-Corbella y María José BAuTiSTA-Cerro Ruiz \\ Universidad Nacional de Educación a Distancia. Facultad de Educación. \\ Departamento de Teoría de la Educación y Pedagogía Social. C/ Juan del Rosal, \\ 14.28040Madrid.mruiz@edu.uned.es; mjbautistac@edu.uned.es
}

Fecha de recepción: enero de 2016

Fecha de aceptación: marzo de 2016

RESUMEN

Se presenta un estudio del concepto de Responsabilidad Social Universitaria (RSU) y de su situación en estos momentos en las universidades españolas. Delimitados la pertinencia y el contenido de la RSU, se lleva a cabo el análisis en 4 ámbitos clave de la educación superior: formación, investigación, gestión y participación social, a partir de indicadores de actuación. Con un estudio exploratorio, se estudia la inclusión de la RSU en la oferta formativa de las universidades españolas, su producción científica en este campo e incorporación a la gestión universitaria. Se concluye que, pese a la relevancia e inicial interés por parte de los equipos de gobierno de estas instituciones, todavía estamos ante un tema no consolidado, aunque se percibe un avance mantenido a lo largo de los años, con diferencias significativas entre los ámbitos de concreción de la RSU. Implantarla en nuestras universidades, junto con un modelo de evaluación, se convertirá en un elemento clave para las universidades, muestra de su capacidad de respuesta a la sociedad.

Palabras clave: universidad; responsabilidad social universitaria; España. 


\section{SUMMARY}

A review of the University's Social Responsibility is introduced, an implementation of corporate social responsibility to the specifics of the institutions of higher education. Once the advisability and content of this concept is defined, 4 key areas in higher education are reviewed: training, research, management and social participation, based on performance indicators. With a descriptive study, the inclusion of USR in the training offering of Spanish universities is analyzed, its scientific output in this field, and its integration to university management. The conclusion is that, despite the relevance and initial interest from the government teams of these institutions, this is yet a not consolidated topic, although a constant improvement maintained over the years is perceived, with significant differences between the areas of the USR. Implementing it in our universities, along with an evaluation model, will become a key factor for the universities, as a sign of its capacity to respond to society.

Key words: universities; social responsibility; Spain.

\section{SOMMAIRE}

On présente une étude du concept de Responsabilité Sociale de l'Université (RSU), et de sa situation actuelle dans les universités espagnoles. Délimité la pertinence et le contenu de la RSU, on effectue l'analyse dans 4 domaines clés de l'enseignement supérieur: la formation, la recherche, la gestion et la participation sociale, sur la base des indicateurs de performance. Avec une étude exploratoire, on étudie l'inclusion de la RSU dans la formation offerte par les universités espagnoles, sa production scientifique dans ce domaine, et l'incorporation dans la gestion des universités. Il est conclu que, malgré la pertinence et l'intérêt initial des équipes gouvernementales de ces institutions, nous sommes encore face à une question non consolidée, même si on observe une progression constant au fil des ans, avec des différences significatives entre les cadres de concrétion de la RSU. L'implanter dans nos universités, avec un modèle d'évaluation, deviendra en élément clef pour les universités, la preuve de sa capacité de réponse à la société.

Mots clés: université; responsabilité sociale de l’Université; Espagne.

\section{INTRODUCCIÓN}

A lo largo de estas últimas décadas los cambios en nuestro sistema universitario han sido continuos, adaptándonos a las nuevas demandas y exigencias orquestadas por organismos supranacionales (UNESCO, 2009; COM, 2006, 2011; Salmi, 2009; Sursock, 2015). A pesar de que hemos implementado una nueva estructura organizativa y metodológica, el actual modelo de Universidad sigue siendo cuestionado y sin terminar de adoptar unos perfiles definidos y consensuados. Entre los diferentes documentos que se han presentado para dirigir este proceso de modernización de 
estas instituciones destaca el Informe 'Estrategia Universidad 2015' (Ministerio de Educación, 2011), al identificar los ámbitos clave que deben ser impulsados por las universidades españolas: la financiación del sistema universitario, la competitividad de las universidades, el incremento de la proyección internacional, la movilidad de todos los actores y el fortalecimiento de su dimensión social. A raíz de este informe y, en especial, de este último punto, el Ministerio de Ciencia e Innovación (s/f) destacó, como prioridad, la responsabilidad de la Universidad española para responder con rapidez y eficacia a las demandas sociales, desempeñando «un papel protagonista en la difusión de posibles soluciones y alternativas a los problemas ambientales, energéticos y económicos a los que se enfrenta la sociedad actual» (MICINN, s/f, 4). Es decir, desarrollar en toda su amplitud su función social. Entre todas, en este artículo vamos a centrarnos en el de la responsabilidad social (RS), dada las consecuencias que se derivan de las decisiones y actuaciones de toda institución universitaria y que, de una forma u otra, está determinando el propio modelo de Universidad que se está gestando.

2. DE LA RESPONSABILIDAD SOCIAL (RS) A LA RESPONSABILIDAD SOCIAL UNIVERSITARIA (RSU)

\subsection{Empresa y responsabilidad social}

Es difícil determinar el momento exacto en el que surgió el concepto de Responsabilidad Social Corporativa (RSC) "aunque algunos autores atribuyen su nacimiento a Sheldon (1923) y otros a Bowen (1953), no hay duda que su mayor auge ha sido desde finales de los años 90, a raíz de los escándalos financieros y el boom de las inversiones socialmente responsables» (Puentes y Mozas, 2010, 77). Para Pinillos y Fernández $(2011,6)$ «todo el movimiento de la responsabilidad empieza con el Pacto Mundial, o Global Compact. Lanzado en el Foro de Davos el 31 enero de 1999 por el ex secretario general de Naciones Unidas, Koffi Annan, el Pacto Mundial supuso un antes y un después en materia de RSC». Otros autores (Guedez, 2010; Cea Moure, 2010) prefieren situar el auge de la idea de RSC en Estados Unidos a finales de la década de los 60 como respuesta a la creciente sensibilización de los ciudadanos sobre su responsabilidad ante las consecuencias de las acciones y decisiones empresariales. En cualquier caso, a lo largo de las últimas décadas del pasado siglo XX, esta mayor conciencia derivó en numerosas acciones sociales con un éxito desigual, pero que, en algunos casos, obtuvieron sonoras victorias. No se cuestionaban la finalidad de toda empresa de obtener beneficios, sino que demandaban la necesaria implicación y contribución de toda organización empresarial a respetar la comunidad y contribuir al desarrollo de sus objetivos.

Ahora bien, no hay unanimidad a la hora de definir Rs, en sus diferentes acepciones (Benavides, Fernández Fernández y Urtiaga de Vivar, 2012). Rubio (2009, 6) presenta la RSC como «[...] un término que hace referencia al conjunto de obligaciones y compromisos, legales y éticos, tanto nacionales como internacionales, 
que se derivan de los impactos que la actividad de las organizaciones producen en el ámbito social, laboral, medioambiental y de los derechos humanos».

Para la Organización Internacional del Trabajo (s/f) se trata de

la manera en que las empresas toman en consideración las repercusiones que tienen sus actividades sobre la sociedad y en la que afirman los principios y valores por los que se rigen, tanto en sus propios métodos y procesos internos como en su relación con los demás actores.

El Consejo Estatal de Responsabilidad Social de las Empresas (CERSE), por su parte, la considera como el

[...] cumplimiento estricto de las obligaciones legales vigentes, la integración voluntaria en su gobierno y gestión, en su estrategia, políticas y procedimientos, de las preocupaciones sociales, laborales, medioambientales y de respeto a los derechos humanos que surgen de la relación y el diálogo transparentes con sus grupos de interés, responsabilizándose así de las consecuencias y los impactos que se derivan de sus acciones (Barrera, 2008, 76).

Ahora, todas ellas presentan los rasgos comunes de voluntariedad en la realización de unas acciones que van más allá de lo establecido en las leyes y normativas, y la consideración de las repercusiones de la actividad de la empresa. Por lo tanto, parece necesaria una orientación y guía que facilite su materialización y que ésta pueda ser razonablemente visible y evaluable.

A partir del lanzamiento del Pacto Global, en 1999, son múltiples las iniciativas que se han encargado de este tema, entre las más relevantes encontramos el Global Reporting Iniciative (GRI) y la ISO 26000. Ambas propuestas proporcionan a toda organización un instrumento necesario para evaluar y valorar el impacto de sus acciones y facilitar la comprensión, transparencia y comparabilidad de la información recogida, base de las futuras memorias de sostenibilidad. Esta información es la que conduce a la toma de decisiones en aquellas acciones que están perjudicando a la comunidad y, por ende, a sí misma. Junto con las propuestas de mejora y desarrollo de estas instituciones.

Si analizamos la situación en nuestro país, la incorporación de la RSC al tejido empresarial ha sido lenta. Desde inicios de la primera década de este siglo se ha venido trabajando desde diferentes instancias para incorporar las prácticas responsables en toda acción empresarial. Ejemplo de este interés es la creación en 2005 del Foro de Expertos en RSE, impulsado por el Ministerio de Trabajo y Asuntos Sociales, configurado por representantes de la Administración, los grupos empresariales, las organizaciones de ciudadanos y la academia. Este órgano derivó, 3 años más tarde, en el CERSE.

Lo cierto es que, a lo largo de estos años, se han sucedido una serie de declaraciones y documentos apoyando la necesidad de contemplar la responsabilidad de las corporaciones, tanto públicas como privadas, con su entorno, como, p. e., el Código Unificado de Buen Gobierno de 2005 o el Informe para potenciar 
y promover la RSE, aprobado por la Comisión de Trabajo y Asuntos Sociales del Congreso de los Diputados, en 2006. Más tarde, también determinará la forma de incorporar la RS a las universidades como instituciones que son, a la vez que a los contenidos de su docencia e investigación. En 2014, la CERSE presentó el documento "Estrategia Española de Responsabilidad Social de las Empresas 2014-2020", dirigido a todas las organizaciones con la intención de «[...] crear un marco común que sirva de referente en materia de RSE a todos y cada uno de los actores que conforman el contexto socioeconómico de nuestro país» $(2014,57)$. Y urge a que toda empresa u organismo elabore y difunda las Memorias e Informes sobre RS, y a incorporar medidas destinadas al buen gobierno.

La RSC tampoco ha sido una cuestión ajena a la normativa, ya que son muchas las leyes que se encargan de aspectos que pueden ser incluidos dentro de este tema: igualdad, accesibilidad, contratos públicos, discapacidad, medio ambiente, etc. Mención especial merece la Ley 2/2011, de 4 de marzo, de Economía Sostenible, que se ocupa tanto de las empresas privadas como de las instituciones públicas y contiene una sección especialmente dedicada a la formación, investigación y transferencia de resultados en el sistema universitario. Acción estrechamente relacionada con el contenido y concepto de la RSC que hemos definido, también mencionado explícitamente en la Ley 14/2011, de 1 de junio, de la Ciencia, la Tecnología y la Innovación, con especial incidencia para la Universidad.

La relevancia de esta tarea impulsó foros en diversas instancias, como es el caso del Foro de Expertos sobre RSE, integrado por representantes de distintos Ministerios, así como por profesionales vinculados al mundo empresarial, al universitario y diferentes organizaciones de la sociedad civil, las cátedras en las universidades y las publicaciones científicas que abordaron los diferentes contenidos de la RSC desde las más diversas perspectivas, logrando entretejer una importante red que aborda la investigación, la reflexión, la comunicación y difusión de todo lo relacionado con esta temática. Destacamos el papel clave que han desempeñado dos iniciativas sociales, ambos casos en el marco de la empresa, centradas en generar el debate necesario y la sensibilidad para atenderlos y desarrollarlos. La primera de ellas es la referida a la actividad de la Confederación Empresarial Española de la Economía Social (CEPES), que desde 1992 centra sus esfuerzos en el desarrollo de la economía social en España, dando visibilidad social e institucional especialmente ante los poderes públicos. La segunda es la labor del Observatorio de RSC, creado en 2004 por organizaciones centradas en el estudio e impulso de la RSC, con el apoyo tanto de organizaciones empresariales, sindicales, ONG, organizaciones de defensa del consumidor, como de universidades.

Tampoco podemos olvidar a Forética como foro clave para la difusión de la RSC en nuestro entorno, que ha supuesto una contribución relevante para el desarrollo de estrategias de RS, tanto en grandes empresas como en PYMES. Al Observatorio de Responsabilidad Corporativa y Sostenibilidad que, a través de su blog Corresponsables, evidencia el dinamismo de este sector y el convencimiento del valor de la dimensión social en toda decisión y actuación empresarial. De esta 
forma, sociedad y empresa van acercándose, apoyándose y beneficiándose mutuamente (Olcese, 2013).

\subsection{Universidad y responsabilidad social}

Sin duda, al mismo ritmo que se introducía el interés en nuestro país por incorporar la RSC en nuestras empresas, la Universidad se involucró a través de su profesorado en el estudio, investigación y formación de la misma. La Universidad, a través de sus docentes, estuvo presente en la creación e impulso de las organizaciones mencionadas en el punto anterior, pero fue mucho más lenta en la acogida e incorporación de estos contenidos en la vida académica de nuestras instituciones (Larrán y Andrades, 2013b, 2015). Fueron las Facultades de Ciencias Económicas y Empresariales las primeras que incorporaron asignaturas sobre la RSC en los Grados y Másteres y en sus propuestas de formación permanente. A su vez, es significativa la creación de cátedras sobre RSC, en estas facultades, avaladas por empresas de la categoría del Banco Santander, Telefónica, INDiTEx o La Caixa. Cátedras que se centran en la investigación de la RSC en el tejido empresarial y económico de nuestro país, y en la difusión y sensibilización de estos temas en la sociedad y, de modo especial, entre los futuros egresados y en los profesionales.

Ahora bien, la RS no se vio únicamente como elemento de estudio y línea de investigación, sino que el paso realmente relevante fue que la Universidad integró, como institución que es, la Rs en su propia estructura organizacional. De este modo, la RSC pasó a ser RS universitaria (RSU). Barañano (2012) percibió esta incorporación de la responsabilidad social y del desarrollo sostenible como un proceso propulsado, sobre todo, "desde arriba" y, en buena medida, "desde dentro». Sin duda, es necesario un cierto empuje institucional, pero también un marco normativo que apoye y ampare las iniciativas en torno a ella. En el caso español, si bien el ámbito empresarial, e incluso el de la administración en general, propiciaron un mayor número de acciones sobre Rs, en el caso universitario este interés llegó más tarde (Larrán y Andrades, 2013b). En este retraso podemos encontrar distintos motivos, por un lado, el intenso debate en el que ha estado sumergida la Universidad desde que se empezara a gestar el EEes. Por otro, entendemos que no puede ser considerada de la misma forma que la RSC. Si el concepto social de la RSC facilitó la contraposición entre el aspecto social y el económico sin lograr integrarlos (Lozano, 2007), no ocurre lo mismo en la RSU, a pesar de las históricas acusaciones a la Universidad sobre su distancia respecto a la sociedad. Lo cierto es que podemos constatar que las instituciones de educación superior han hecho de éste un tema protagonista y que es explícito tanto en su misión como en sus funciones. Por ello, no es arriesgado afirmar que la Universidad no se ha visto excesivamente interpelada a denominar bajo un nombre, ajeno a la propia institución, aquello que ya venían desarrollando (programas de igualdad, de atención a la diversidad, de mejora de relaciones laborales, etc.) de manera habitual y entendiéndolo como una de sus funciones indiscutibles. Aunque esto no impide que se exija 
un mayor compromiso con la sociedad y con la contribución a un nuevo modelo de desarrollo más equilibrado y sostenible (MEC, 2011). La Ley 2/2011 sobre Economía Sostenible alude expresamente a la Universidad como institución clave en la incorporación de la RSC en nuestro país y establece objetivos con una vinculación directa con la RSU, al abogar por una gobernanza universitaria más transparente y eficaz. Desde las diversas instancias se aboga por que las universidades pongan en marcha un sistema de gobierno eficaz, reforzando su autonomía y su compromiso con la responsabilidad y rendición de cuentas (García Benau, 2014), que no sólo atañe a la gestión económica y de recursos de esta institución, sino también a la docencia e investigación de la que también debe rendir cuentas a la sociedad en cuanto a los resultados obtenidos (egresados, formación, transferencia de conocimientos, producción científica, etc.).

Por lo que respecta a la legislación universitaria, la Ley Orgánica de Universidades, de 2001 (LOU), recoge en su exposición de motivos elementos que pueden ser leídos en clave de Rs, a la vez que vincula la autonomía universitaria con la rendición de cuentas a la sociedad que la impulsa y la financia. Más tarde, la Ley Orgánica 4/2007, de 12 de abril, por la que se modifica la LOU (LOMLOU), también destaca esta vinculación con la sociedad, señalando que

la formación en cualquier actividad profesional debe contribuir al conocimiento y desarrollo de los derechos humanos, los principios democráticos, los principios de igualdad entre mujeres y hombres, de solidaridad, de protección medioambiental, de accesibilidad universal y diseño para todos, y de fomento de la cultura de paz (art. 3.5).

Punto que también incluye, como es lógico, el Real Decreto 1393/2007, de 29 de octubre, por el que se establece la ordenación de las enseñanzas universitarias oficiales, y su modificación, Real Decreto 861/2010, de 2 de julio.

Por otro lado, no debemos olvidar la 'Estrategia Universidad 2015', ya mencionada, que indica que las universidades deben asumir como tercera misión la RSU, haciendo hincapié en la 'misión formativa de la Universidad' señalando que «el compromiso con la responsabilidad social debe impregnar el conjunto de los procesos formativos en sus distintas modalidades» (Ministerio de Educación, 2011, 87).

Sin duda, esta estrategia y las normativas anteriormente mencionadas recogen la creciente demanda social de mayor eficacia, eficiencia y transparencia de las instituciones públicas ante el incremento de la conciencia del impacto de toda organización en la sociedad. Todo ello ha contribuido a que las universidades no permanecieran ajenas a estos requerimientos, impulsando nuevas políticas y estrategias en la docencia, investigación, transferencia del conocimiento y gobernanza (Naval y Ruiz-Corbella, 2012). Ahora, "su puesta en práctica requiere una comprensión amplia de su significado y de su función como posible instrumento de gestión universitaria, lo que implica que junto con las iniciativas de acciones sociales concretas, se tenga que definir también un cambio en el enfoque de dirección de las universidades» (García Benau, 2014, 9). Cuestión que tampoco es 
una novedad para la Universidad, ya que, de una forma u otra, siempre ha estado presente como parte esencial de su misión, como ya se ha comentado antes. Sin embargo, no hay unanimidad a la hora de definir este concepto en este ámbito terciario, denominándolo indistintamente RSU, tercera misión o dimensión social de la Universidad. Evidentemente no es lo mismo tratar este aspecto desde una terminología u otra, ya que cada una de éstas incide en un ámbito y/o dimensión, pero lo que las une es la creciente conciencia social del impacto de nuestras acciones y de su innegable papel en el desarrollo social, económico y cultural en el contexto en el que están insertas.

Como entidad que es, requiere una modernización de su gobierno (gobernanza), de su modelo de financiación y rendición de cuentas, su gestión, su capacidad de empleabilidad, su capacidad de interacción con la sociedad, con otras empresas y, en especial, con otras universidades, lo que conlleva que la Rs en una organización universitaria se defina como la «reconceptualización del conjunto de la institución universitaria a la luz de los valores, objetivos, formas de gestión e iniciativas que implican un mayor compromiso con la sociedad y con la contribución a un nuevo modelo de desarrollo más equilibrado y sostenible» (Comisión Técnica de la Estrategia Universidad 2015, 2011, 11). Enfoque que exige su aplicación tanto en su gestión interna como en todas sus actuaciones exteriores en cualquiera de sus dimensiones: social, económica, ambiental, cultural..., ya sea en su relación con las personas o el entorno. De esta forma, toda institución universitaria deberá trabajar atendiendo a 4 ámbitos que responden a los ejes de toda RSU: campus responsable, gestión social del conocimiento, formación profesional y ciudadana y participación social (Valleys, 2009). Sin duda, y en este punto coinciden todos los actores sociales, es responsabilidad ineludible de toda Universidad liderar la generación de conocimientos y destrezas necesarias para afrontar los problemas sociales, económicos, ambientales, culturales, etc., a los que nos estamos enfrentando, mejorando la capacidad de la ciudadanía para responder a estos desafíos. Además de atender a todos los colectivos que acceden a este nivel educativo (Egido, Fernández Díaz y Galán, 2014). Nuestras instituciones ya no tienen el monopolio del saber ni de la ciencia, pero sí la capacidad necesaria para liderar el cambio social que se demanda, la investigación y la generación de conocimiento en colaboración con todos los grupos de interés.

\section{LA RS EN LAS UNIVERSIDADES}

La mayor sensibilidad y presencia en documentos oficiales de temas relativos a la Rs ha facilitado que las universidades intensificaran esfuerzos que ya venían desarrollando en estas áreas, o bien iniciaran estrategias en este sentido, tal como ya hemos mencionado. Ahora, ¿cómo podemos valorar la incorporación y acciones específicas de RS en las universidades españolas? Está claro que encontramos una evidente disponibilidad y sensibilidad de los diferentes sectores que intervienen en la comunidad universitaria a incluir la RS en la gestión de estas organizaciones. Sin 
embargo, para poder valorar este extremo el objetivo de este trabajo se centra en identificar y analizar la presencia de la RSU, y su evolución, en las acciones desarrolladas en los cuatro ámbitos clave de toda institución universitaria: la formación, la investigación, la gestión y la participación social. Para ello, en este trabajo únicamente se van a utilizar como descriptores identificativos de esta realidad los referidos a la 'responsabilidad social' (RS), bien sea nombrada en las diferentes fuentes como 'responsabilidad social corporativa' (RSC), 'responsabilidad social empresarial o de la empresa' (RSE) o 'responsabilidad social universitaria' (RSU).

Nos interesa la información del conjunto de las universidades españolas incluidas en el Registro de Universidades, Centros y Títulos (RUCT) del Ministerio de Educación, Cultura y Deporte (2015), que recoge un total de 84 instituciones en todo el territorio. 50 entidades públicas y 34 privadas, de las que 16 han iniciado su andadura en lo que va de siglo. Su actividad se desarrolla en 236 campus universitarios con una oferta académica de 2.413 grados y 2.758 másteres universitarios. Se trata, como podemos ver en el Gráfico 1, del mayor crecimiento de la enseñanza privada universitaria en toda nuestra historia.

\section{GRÁFICO 1. IMPLANTACIÓN Y EVOLUCIÓN DE LAS UNIVERSIDADES PÚBLICAS Y PRIVADAS EN ESPAÑA}

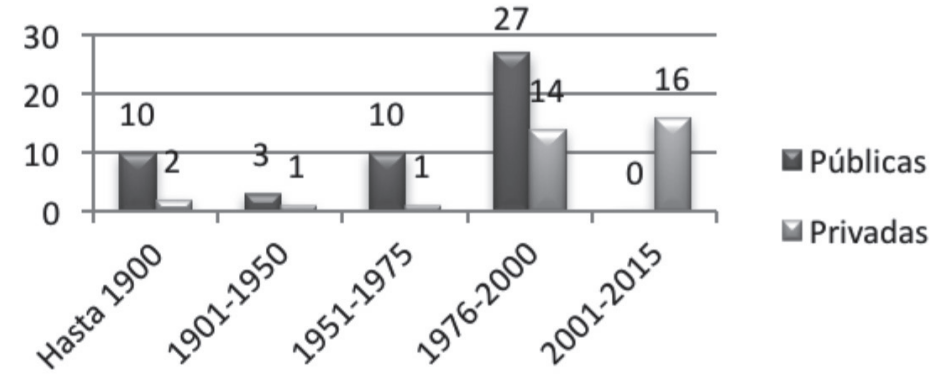

FUENTE: RUCT, 2015.

Como ya hemos señalado, a lo largo de este siglo ha sido explícito el creciente interés tanto de la Administración Pública como de los órganos consultivos de estas instituciones, por apostar decididamente por la inclusión de la Rs en las decisiones y actuación de toda institución universitaria. Entre éstos, destacamos las acciones de:

- El Consejo de Rectores de Universidades Españolas (CRUE), asociación que reúne a la mayoría de las universidades españolas (50 públicas y 26 privadas), que viene trabajando desde hace décadas para el desarrollo de esta institución y la consolidación de la interacción de la Universidad con el tejido productivo y social de nuestro país. Es el principal interlocutor de las universidades con el Gobierno central y los autonómicos. En esta 
institución la RSU se encuentra integrada en 3 de las 10 Comisiones Sectoriales que marcan su línea de actuación. En concreto, en la CRUE-Sostenibilidad (antigua CADEP), la CRUE-Internacionalización y Cooperación (antigua CICUE) y la CRUE-Asuntos Estudiantiles (antigua RUNAE). Esta dispersión genera una pérdida de visibilidad en cuanto a las actuaciones de Rs que lleva a cabo. Una de las acciones con mayor visibilidad sobre este tema fue la participación en la XxIV Cumbre Iberoamericana de Jefes de Estado (Veracruz, 2014), en la que los rectores de 36 países presentaron la Carta Universia Río 2014, que refleja las tendencias de la Universidad de este siglo y sus propuestas de acción, que girarán en torno a la internacionalización, digitalización, colaboración universidad-empresa, innovación y RS.

- La Conferencia de Consejos Sociales de Universidades (CCSU), asociación que reúne a estos órganos de participación universitaria, enlaces de estas instituciones con la sociedad. Entre sus centros de interés está la RSU, gestionada a través de la Comisión de Relaciones con la Sociedad, que ha creado una red dirigida a promover la RSU y difundir buenas prácticas. Esta acción la operativiza la red de Consejos Sociales de las Universidades Públicas de Andalucía, que son los artífices de las Jornadas de RSU, la I Jornada Internacional de RSU (Cádiz, 2014) y del Observatorio de RSU.

En esta misma línea de trabajo, las universidades públicas catalanas (ACUP) pusieron en marcha en abril de 2015 la Comissió de Responsabilitat Social Universitària (RSU), con el objetivo de incorporar y evaluar la RSU en la estrategia de estas instituciones, a la vez que delimitar correctamente su contenido. Comisión aún muy joven para poder valorar la eficacia de sus actuaciones. Ahora, la puesta en marcha de esta iniciativa ya nos indica el interés de estas universidades por la RS.

\section{PRESENCIA DE La RS EN LAS UNIVERSidades ESPaÑolas}

\subsection{Metodología}

Este trabajo se desarrolla enmarcado en un estudio exploratorio, ya que pretende la recogida, organización y análisis de la información en un ámbito concreto, con el objetivo de identificar la situación real de la RS en nuestras universidades y plantear futuras investigaciones en este campo a partir de los conceptos y las prioridades detectadas (Galán Amador, 2013). A partir de análisis estadísticos básicos, se aporta la recopilación y presentación sistematizada de los datos, de tal forma que ofrezca una idea clara de la acción estudiada. Para llevar a cabo este análisis se han identificado los ámbitos y sus indicadores que describen la actividad de estas instituciones terciarias (Valleys, 2009; Gaete Quezada, 2011, entre otros), identificándose en cada uno de éstos los indicadores y, a partir de ellos, las actuaciones específicas en las que se ha incluido bien la Rs como objeto de aprendizaje y/o investigación, o como objetivo de una acción específica (Tabla 1). 
MARTA RUIZ-CORBELLA Y MARÍA JOSÉ BAUTISTA-CERRO RUIZ

TABLA 1. ÁMBITOS Y CONTENIDO DE RSU

\begin{tabular}{|l|l|}
\hline \multicolumn{1}{|c|}{ Ámbito } & \multicolumn{1}{c|}{ Contenidos } \\
\hline Formación & $\begin{array}{l}\text { Asignaturas } \\
\text { Postgrados } \\
\text { Cátedras Rsu }\end{array}$ \\
\hline Investigación & $\begin{array}{l}\text { Publicaciones científicas } \\
\text { Tesis doctorales } \\
\text { Proyectos de investigación competitivos }\end{array}$ \\
\hline Gestión & $\begin{array}{l}\text { Incorporación en el organigrama } \\
\text { Memorias de Rsu }\end{array}$ \\
\hline Participación social & $\begin{array}{l}\text { Observatorios de Rsu } \\
\text { Acciones específicas }\end{array}$ \\
\hline
\end{tabular}

Para obtener los datos se ha recurrido a distintos tipos de fuentes. Por un lado, los informes y memorias de proyectos de investigación avalados por el Ministerio de Educación (proyectos financiados por este Ministerio en el Programa de Estudios y Análisis). Estos proyectos se han localizado en la web del Ministerio a través de la indagación por palabras clave. Por otro lado, se ha realizado una búsqueda sistemática de información (a través de las mismas palabras clave) en las bases de datos escogidas para el análisis de la producción científica, DIALNET e ISOc, ya que este trabajo se centra exclusivamente en las publicaciones científicas españolas. Igualmente, para conocer el ámbito de gestión y participación social se ha recurrido a la información presente en las webs institucionales de cada Universidad. En cuanto a la valoración de las tesis doctorales se ha trabajado con TESEO, DIALNET y Tesis en Red, como fuentes que indizan un mayor número de tesis doctorales de nuestras universidades, especialmente todas las asociadas a la CRUE.

En cuanto al tiempo, el intervalo con el que se ha trabajado abarca desde enero de 2000 a junio de 2015, momento en que se cierra la recogida de información. Y destacar que la recogida y análisis de datos se ha realizado desde septiembre de 2014 hasta junio de 2015, y el resultado obtenido aporta una imagen de la RSU en nuestras universidades más precisa para la formulación de futuras investigaciones.

\subsection{Análisis de la RSU en las universidades españolas}

\subsubsection{Formación}

Aunque el análisis del ámbito de la formación en las universidades es tremendamente complejo, sí podemos avanzar la valoración de la incorporación de la RS en la formación de los estudiantes a partir de 3 indicadores: las asignaturas que se imparten en las diferentes titulaciones, los programas de postgrado que se ofertan 
y las cátedras universitarias que se promueven. En todos estos casos es relevante identificar el área de conocimiento en la que se adscribe cada uno de estos indicadores, además de los rasgos identificativos en cada uno de ellos.

Como primer elemento para valorar la incorporación de la RS como contenido formativo y la sensibilidad de la comunidad académica ante esta demanda social, destacamos las asignaturas que se ofertan en los planes de estudio de grados y postgrados. Para esta primera aproximación acudimos a los estudios realizados por la Cátedra Javier Benjumea de la Universidad Pontificia de Comillas sobre la situación actual de la RSE y la ética empresarial en la educación superior española (2009) y por Larrán y Andrades (2013b), que analizaron más de 1.018 titulaciones de las universidades españolas identificando la oferta de asignaturas de RSE. En las titulaciones estudiadas, únicamente detectaron 269 asignaturas que recogieran estos descriptores. Destacan que las asignaturas que tratan de forma exclusiva la RSC son escasas en el nivel de grado, destacando la RSC en los programas de estudios de postgrado (Ciencias Económicas, Empresariales, Turismo y Magisterio) (Castillo, 2010; Larrán y Andrade, 2013b). Ahora bien, si analizamos esta inclusión desde la valoración de alguno de los indicadores que conforman la Rs (sostenibilidad, ética, medio ambiente, tratamiento de la igualdad o diversidad) la presencia de asignaturas se dispara.

Por otro lado, de los datos que aportan estos estudios, destacamos que la Universidad privada presenta un mayor porcentaje de titulaciones con, al menos, una asignatura con descriptores sobre Rs o ética en un 79,7\% frente al 15\% en la pública, primando esta oferta en escuelas y facultades relacionadas con la empresa, la ingeniería, la salud, el turismo, las finanzas y la comunicación:

Gráfico 2. Titulaciones CON, Al menOS, UnA ASignatura CON DESCRIPTORES SOBRE RS O ÉTICA

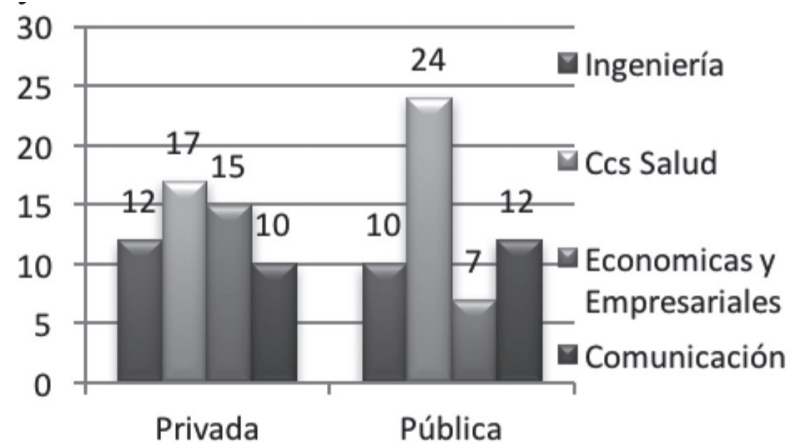

Fuente: CÁtedra Javier Benjumea (2009) Situación actual de la RSE y la ética empresarial en la educación superior española. 
Si nos centramos en la oferta de postgrados relacionados con la RSC nos encontramos, de acuerdo a los datos facilitados por RUCT (MECD, 2015), únicamente con 6 másteres universitarios sobre RSC impartidos por la UNED, en convenio con la Jaume I de Castellón, la Universidad de Vigo, la Internacional de La Rioja, la Universidad Loyola de Andalucía y la Oberta de Catalunya. Si acudimos a la base de datos de UNIVERSIA y de ANECA, esta búsqueda apunta un mayor número de titulaciones, pero estamos ante una información de escasa fiabilidad al no permitir delimitar la búsqueda, lo que impide un mejor análisis. Ahora bien, lo que sí está claro es que la oferta es escasa, justificándose el elevado número aportado por ambas instituciones a la ausencia de filtros para perfilar correctamente la búsqueda. Otro elemento que se confirma es la concentración de estas propuestas en el área de conocimiento de las ingenierías, las ciencias de la salud o las ciencias empresariales. Y de forma muy puntual en otros estudios.

Si nos fijamos en las asignaturas en este nivel de postgrado, apoyándonos en este caso en los estudios ya mencionados de la Cátedra Javier Benjumea (2009) y Castillo (2010), de los 48 centros analizados en el nivel de postgrado, el $41 \%$ de las universidades imparten contenido relativo a la RSC, mientras que en las Escuelas de Negocio lo imparten el 44\%. Si nos centramos ya en asignaturas específicas, comprobamos que en las universidades únicamente en 10 casos se oferta una materia relativa a este contenido, denominándose RSC únicamente en 4 casos. En cambio, en las Escuelas de Negocio, este dato asciende a 48, impartiéndose 23 asignaturas bajo este título. A la vez, se han impulsado titulaciones específicas sobre RSC, y con temas relacionados con la comunicación, la ética, el desarrollo sostenible y/o la sostenibilidad o el medio ambiente y la calidad. Se ha introducido esta perspectiva en especialidades de MBA, comunicación y marketing, relaciones públicas, sin olvidar los estudios de calidad, finanzas, recursos humanos, acción social y participación ciudadana, medio ambiente, TIC y en postgrados de la rama sanitaria. Sin embargo, en las titulaciones de educación, este indicador no aparece, salvo asignaturas relativas a derechos humanos, género o desarrollo sostenible.

Por último, debemos atender a una figura relativamente reciente, de sumo interés para el impulso de determinadas líneas de investigación que interesan a la sociedad y a la Universidad, avalada, y en muchas ocasiones financiada, por organismos y/o empresas reconocidas socialmente. Nos referimos a las cátedras universitarias, que surgen con la finalidad de promover y desarrollar actividades de reflexión, investigación, formación y divulgación en un ámbito concreto. La creación de estas cátedras universitarias surge siempre alrededor de temas emergentes o que interesa potenciar por su especial interés social. De ahí que en este estudio valoraremos si existen cátedras en las universidades españolas centradas en la RSC o en la RSU, lo que aportaría más información sobre su relevancia.

En torno a la RS se identifican únicamente cátedras de RSC y las cátedras de Ética empresarial (Tabla 2). Con el fin de no duplicar innecesariamente la información, no incluiremos las cátedras que abordan temas específicos de la Rs, como las energías renovables, la sostenibilidad y el desarrollo sostenible, los derechos 
humanos, la ética, la economía solidaria, el buen gobierno o gobierno corporativo y el medio ambiente.

TABla 2. CÁTEDRAS UNIVERSITARIAS DE RS

\begin{tabular}{|l|l|l|}
\hline \multirow{5}{*}{ Patrocinador } & \multicolumn{1}{|c|}{ Título } & \multicolumn{1}{c|}{ Universidad } \\
\hline & RS & Francisco de Vitoria \\
\cline { 2 - 4 } & RSC & Universidad de Málaga \\
\cline { 2 - 4 } & RSC & Castilla-La Mancha \\
\cline { 2 - 4 } & Responsabilidad Social de la Empresa & Nebrija \\
\cline { 2 - 4 } & RSC & Alcalá \\
\cline { 2 - 4 } & RSU & Girona \\
\cline { 2 - 4 } & $\begin{array}{l}\text { Iberoamericana de Dirección de } \\
\text { Empresas y RSC }\end{array}$ & Salamanca \\
\hline \multirow{2}{*}{ Telefónica } & $\begin{array}{l}\text { Responsabilidad Corporativa y } \\
\text { sostenibilidad }\end{array}$ & UNED \\
\hline \multirow{2}{*}{ La Caixa } & $\begin{array}{l}\text { Responsabilidad Social de la Empresa y } \\
\text { Gobierno Corporativo }\end{array}$ & IESE-Universidad de Navarra \\
\hline INDITEX & Responsabilidad Social & A Coruña \\
\hline Mango & Responsabilidad Social Corporativa & Pompeu Fabra \\
\hline- & RSC & Murcia \\
\hline- & Ética, Económica y Empresarial & Pontificia de Comillas \\
\hline
\end{tabular}

FuENTE: Páginas webs de las universidades.

A partir de estos datos se confirma el interés y sensibilidad por la incorporación de la Rs en nuestras universidades, tanto en la gestión, como en la docencia, junto con el desarrollo de iniciativas que consolidan esta perspectiva. La relevancia de las empresas que avalan estas iniciativas respalda el interés social de este contenido. A pesar del gran avance que se puede constatar, sí que se identifican unas áreas de conocimiento sensibilizadas en Rs, frente a otras que aún no la han abordado. El área de la economía, las finanzas o la empresa, junto con la ingeniería o las ciencias ambientales -turismo se une a esta área-, son los colectivos más interesados y activos en RS. Las acciones sustentadas en una dimensión ética, su ámbito de aplicación en el mundo de la empresa y los negocios son también una 
línea de interés muy presente en ellas. Ahora bien, como ya hemos mencionado, la RSU aún no está presente de forma significativa en este tipo de acciones.

\subsubsection{Investigación}

\subsubsection{Publicaciones}

En toda Universidad, uno de los ámbitos de actuación clave es la investigación, identificándose las publicaciones científicas como un claro indicador de calidad. Para valorar un área científica es necesario realizar un análisis bibliométrico de la misma para analizar su impacto real, su vitalidad, los temas y perspectivas que abordan, los autores, los años de productividad, etc. Si en el apartado anterior hemos detectado que la Rs interesa en un sector muy determinado de la Universidad y en unas determinadas áreas de conocimiento, con el análisis de las publicaciones científicas comprobaremos si esta tendencia continúa presentándose, y si existe alguna otra corriente no detectada en el punto anterior.

En este estudio bibliométrico nos centraremos exclusivamente en la producción científica publicada en España, por lo que acudiremos a las 2 bases de datos reconocidas en nuestro entorno: DIALNET (Universidad La Rioja) e ISOC (Consejo Superior de Investigaciones Científicas). La búsqueda se desarrolló a partir de 3 descriptores: 'Responsabilidad Social Corporativa', 'Responsabilidad Social Empresarial' y 'Responsabilidad Social Universitaria', además de la búsqueda booleana con los términos responsabilidad, social, universidad, universitaria en un arco temporal entre los años 2000-2015.

En la base de datos DIALNET, los resultados de los 2 primeros descriptores, RSC y RSE, nos muestran unos datos que avalan el interés sobre este tema. En ambos casos las contribuciones se inician en 2002, de forma sostenida hasta la actualidad. Sin embargo, al introducir el descriptor 'Responsabilidad Social de la Empresa', estas publicaciones se inician en 2007. Esta diferencia temporal significativa puede deberse a la utilización mucho más amplia de la RSC frente a RSE, aunque es un punto que debe ser analizado con mayor profundidad. También debemos tener en cuenta, tanto con un descriptor como con otro, que muchas referencias se repiten en ambas búsquedas. En las 3 propuestas se recogen tanto artículos, capítulos de libros, monografías, actas de congresos como tesis doctorales. Llama la atención la disparidad de resultados entre ambas bases de datos (Tabla 3), que se entiende al trabajar cada una de ellas con fuentes distintas, tanto relativas a revistas, como a libros, actas de congresos, etc., a la vez que a la capacidad discriminante de cada buscador. 
TABla 3. N. ${ }^{\circ}$ DE DOCUMENTOS A PARTIR DE LOS DESCRIPTORES RSC Y RSE

\begin{tabular}{|l|c|c|c|}
\hline & RSC & RSE & RS de la empresa \\
\hline DIALNET & 1.016 & 468 & 618 \\
\hline ISOC & 434 & 610 & 738 \\
\hline
\end{tabular}

FUENTE: DIALNET E ISOC.

Para poder valorar el contenido y relevancia de la Rs en el ámbito de la economía y la empresa, analizaremos los datos recogidos en DIALNET con el descriptor RSC (Tabla 4), al ser el más numeroso y, por ello, recoger de forma más completa la realidad que estamos estudiando. A partir de este análisis podremos valorar y comparar la situación de la RSU, objetivo de este artículo.

TABla 4. COMPARACIÓN DE LOS DOCUMENTOS A PARTIR DE LOS DESCRIPTORES RSC Y RSE

\begin{tabular}{|c|c|c|c|c|c|c|}
\hline DIALNET & Inicio & \multicolumn{4}{|c|}{ Número } & Total \\
\hline Descriptor & año & artículos & capítulos & libros & $\begin{array}{c}\text { tesis } \\
\text { doctorales }\end{array}$ & documentos \\
\hline RSC & 2002 & 737 & 228 & 28 & 23 & 1.016 \\
\hline RSE & 2002 & 368 & 90 & 5 & 5 & 468 \\
\hline RS de la empresa & 2007 & 360 & 180 & 70 & 8 & 618 \\
\hline
\end{tabular}

FUENTE: DIALNET.

En estos 13 años en los que el área de la economía y la empresa se interesaron por la RS se han vivido muchos cambios y se han ampliado enormemente las posibilidades de la acción empresarial en este campo. Desde 2002 en el que se empezó a investigar sobre Rs en la empresa, el descriptor ha sido plenamente incorporado en este ámbito de trabajo y de investigación. Es un tema que interesa, por lo que se ha introducido en la formación de los futuros profesionales, como ya hemos visto, a la vez que forma parte de los intereses de la investigación de los profesionales y de los académicos. A pesar de ser una temática joven, los datos que se han recogido avalan esta afirmación y la tendencia sostenida de su producción científica. Aunque también refleja la influencia del contexto socioeconómico vivido, lo que nos lleva a comprender, a partir de 2013, el descenso de esta producción. No olvidemos que la producción científica lleva tiempo desde que se elabora hasta que se edita, por lo que este cambio de comportamiento en la dinámica de la investigación comenzó uno o dos años antes. Para analizar brevemente esta afirmación, 
recogemos la evolución de este descriptor a lo largo de estos 13 años, los temas que interesan y la adscripción de las revistas que los publican (Grafico 3).

Grafico 3. EVOluCión DE LAS PUBliCACIONES CON EL DESCRIPTOR RSC

\section{№ de publicaciones}

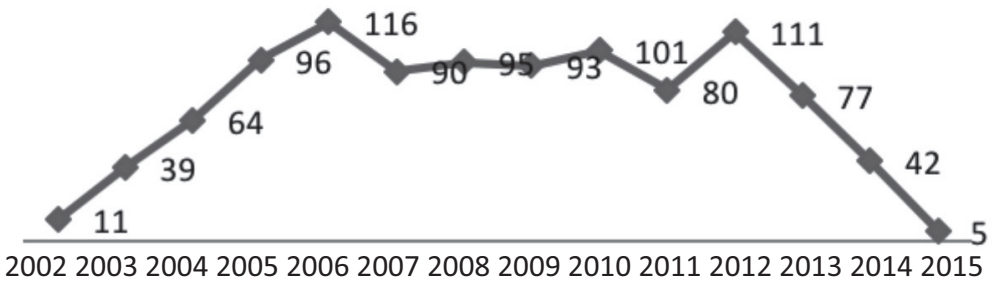

FUENTE: DIALNET.

Aunque debemos ser prudentes a la hora de interpretar este gráfico, sí que nos lleva a concluir el rápido ascenso de las temáticas que abordan la Rs, hasta alcanzar una aparente estabilidad y consolidación de este contenido, abortado en gran parte por la intromisión de la crisis financiera y económica a todos los niveles, tal como sugeríamos antes. La Rs fue uno de los muchos elementos que sufrió recortes en las actuaciones de las empresas. Ahora bien, a pesar de esta realidad, y de la disminución de publicaciones, estamos ante un contenido que interesa, ejemplo de ello es su permanencia y el planteamiento de nuevas perspectivas. Además de contar con jornadas sobre RSE, una revista centrada exclusivamente en esta temática, Revista de Responsabilidad Social de la Empresa (Fundación Luis Vives), tesis doctorales, etc. Será necesario revisar de nuevo la producción científica sobre RSE dentro de, al menos, 3 años para valorar si la tendencia que aquí exponemos se mantiene y se recupera la producción a niveles del quinquenio 2005-2010, o si estamos ante una nueva moda del ámbito empresarial, que no ha llegado a calar en el mundo académico y que, poco a poco, desaparecerá.

En cuanto al área de conocimiento al que pertenecen las revistas científicas en las que se ha publicado esta producción, destaca el área de las ciencias económicas y empresariales, pasando a un segundo lugar, y con gran diferencia, el ámbito jurídico y el de la comunicación. 
GRÁFICO 4. REVISTAS EN LAS QUE SE PUBLICAN TEMAS SOBRE RSC

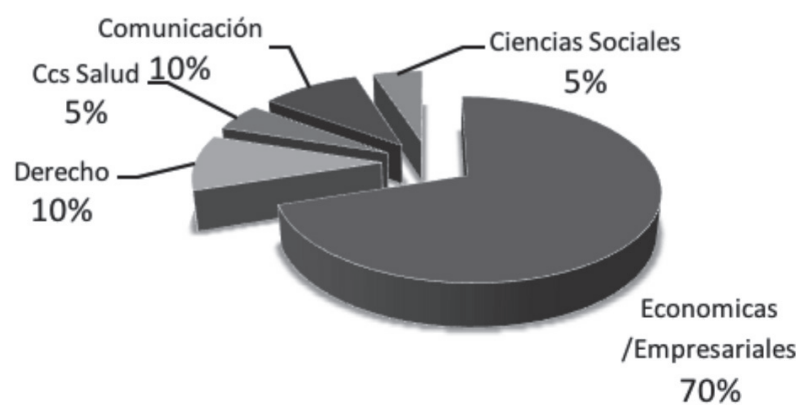

FUENTE: DIALNET.

En cuanto a los temas que han permanecido a lo largo de estos años son los relativos a empresa, mercado, sostenibilidad, medio ambiente y energía, marketing, recursos humanos. A partir de 2009-2010 repuntan los relativos a ética y códigos de ética, derechos humanos, sector financiero, comunicación-imagen, buenas prácticas. Y en estos últimos años la economía social, el e-comercio, ocio y turismo, salud laboral. Como resulta lógico, estos estudios responden a los problemas que afectan al ámbito empresarial, y los intereses que van surgiendo en los diferentes modos de comprender y atender la economía, de ahí la interesante evolución de la temática de estos estudios.

Si nos centramos ahora en la RSU, bajo este descriptor y en las dos bases de datos mencionadas, DIALNET recupera 547 entradas e ISOC únicamente 53. Por lo que procedemos a realizar el estudio con los datos que aporta la primera. En esta base de datos realizamos la búsqueda tanto a partir del descriptor de RSU, como con la búsqueda booleana con los términos responsabilidad, social, universidad y universitaria. Esta última búsqueda fue descartada, al no discriminar los temas que nos interesa, introduciendo excesivo ruido.

TABla 5. COMPARACIÓN DE LOS DOCUMENTOS A PARTIR DEL DESCRIPTOR RSU

\begin{tabular}{|c|c|c|c|c|c|c|}
\hline Descriptor & $\begin{array}{c}\text { año } \\
\text { inicio }\end{array}$ & artículos & capítulos & libros & $\begin{array}{c}\text { Tesis } \\
\text { doctorales }\end{array}$ & $\begin{array}{c}\text { Total } \\
\text { documentos }\end{array}$ \\
\hline RSU & 2000 & 415 & 91 & 21 & 20 & 547 \\
\hline R+S+U & 2000 & 2.449 & 437 & 72 & 20 & 2.978 \\
\hline R+S+ universitaria & 2005 & 413 & 91 & 20 & 20 & 544 \\
\hline
\end{tabular}

FUENTE: DIALNET. 
Con este descriptor, RSU, seguimos los mismos parámetros de análisis que con el anterior. En concreto, su evolución a lo largo de los últimos años, los temas que interesan y la adscripción de las revistas que los publican. En cuanto al primer criterio, evolución del interés de la RSU manifestada en la publicación de artículos científicos, nos encontramos con que estamos ante un interés del ámbito universitario que arranca ya en 1995 -aunque este año no era objeto de este estudio-, identificando, desde esa fecha hasta 1999, 5 contribuciones en las que se planteó la RS de la docencia universitaria, la función de la Universidad o la RS del gobierno universitario. Todos ellos temas nucleares de la RSU, sin embargo, es significativo que en ninguno de estos casos se detecta continuidad en la investigación sobre la RS por parte de los autores que las firman. A diferencia de la RS, la RSU inicia la publicación de artículos científicos en el 2000, con una clara influencia de la dinámica latinoamericana generada en este campo.

GRAFICO 5. EVOluCIÓN DE LAS PUBLICACIONES CON EL DESCRIPTOR RSU

\section{№ de publicaciones}

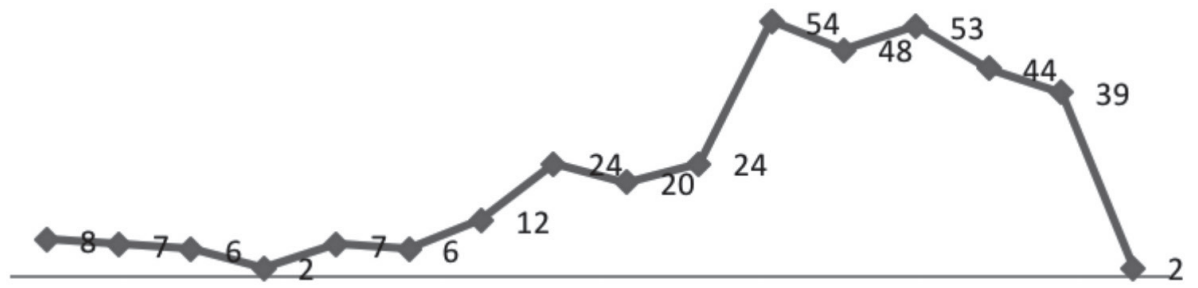

2000200120022003200420052006200720082009201020112012201320142015

FUENTE: DIALNET.

Al analizar la evolución y contenido de esta temática detectamos, en primer lugar, un número inferior de contribuciones, que se reducen a 366 bajo ese descriptor temático, al descartar contribuciones alejadas a la RSU. El interés por ella se incorpora muy lentamente en el ámbito académico, y no llega a evidenciarse de forma clara hasta la década del 2010, que coincide con la implantación del EeEs, junto con la consolidación que expusimos en este mismo análisis en la RS. A la vez se comprueba el mismo descenso de investigación en esta temática, que coincide en el tiempo con la problemática económica que se ha vivido en la sociedad española. Ahora bien, también podemos explicar esta situación como una consecuencia de la falta de formación en Rs y la falta de tiempo ante temas urgentes que deben resolverse y atenderse, tal como explican Larrán y Andrades (2013b). Ahora, esto debe combinarse con la fortaleza de este descriptor, que, como destacan también 
estos mismos autores, la RSU se valora por su capacidad de mejorar la imagen y reputación de las universidades, la recuperación del valor de compromiso social intrínseco a su misión, así como su competitividad.

En cuanto al área de conocimiento en la que se publican estos artículos (Gráfico 6), destacan las revistas de educación, especialmente las que se centran en estudios sobre la educación superior. Y el resto se divide, de forma más o menos homogénea, llamando la atención el interés desde el área de la enfermería o la de la comunicación. En las contribuciones publicadas en las revistas de educación, los autores provienen de todas las áreas del conocimiento (pedagogía, ingeniería, empresariales, etc.), detectándose en este punto un claro interés desde todas las dimensiones de la investigación y la mejora de la práctica educativa específica, a la vez que se atiende a todos los ámbitos de la vida universitaria.

Gráfico 6. REVISTAS EN LAS QUE SE PUBLICAN TEMAS SOBRE RSU

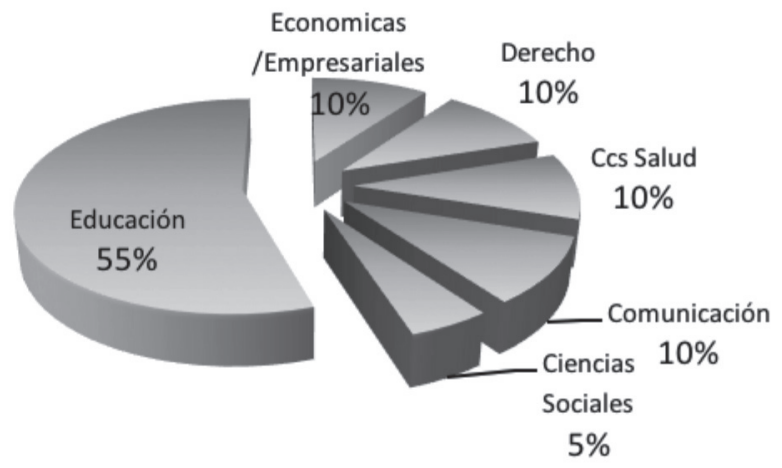

FUENTE: DIALNET.

En cuanto a temáticas que se abordan se inician con temas relativos al gobierno de la Universidad, introduciéndose rápidamente en aspectos que se derivan del diseño de titulaciones (perfil profesional, formación ética, empleabilidad...), la percepción de los diferentes grupos de interés en torno a la Rs, las actitudes éticas, la misión de la Universidad, sostenibilidad, el voluntariado y, más recientemente, el aprendizaje servicio como medio para acercar esta institución a la sociedad.

Este interés coincide con el estudio publicado por Pacenza y Silva Peralta (2013), en el que se avala esta tendencia creciente de publicaciones sobre RSU, ahora no debemos perder de vista, tal como se destaca, que predominan los autores "transeúntes", al ser investigadores que solo han publicado una única vez sobre esta temática, a la vez que también es escasa la colaboración entre ellos. Esto nos muestra la falta de consistencia en esta línea de trabajo, que debemos revisar de forma periódica para confirmar si se consolida o si desaparecerá. En suma, estamos 
ante un ámbito de estudio, investigación y actuación que interesa, pero que no acaba de consolidarse, salvo en contados autores.

\subsubsection{Tesis doctorales}

Si revisamos las bases de datos de tesis doctorales, nos encontramos que sobre RSC, de acuerdo a TESEO, se han defendido 105 trabajos desde el 2001, predominando las Facultades de Económicas y Empresariales en este punto. Sin embargo, si buscamos tesis doctorales en torno a la RSU, se limitan a 11 defendidas a partir del 2009 (Tesis en Red [TDR] recoge únicamente 8). Los Programas de Doctorado que impulsan estas investigaciones provienen de Facultades de Empresariales (4), de Educación (4), Psicología (2) y Sociología (1). En cuanto a las Universidades no se encuentra ningún foco de interés, ya que las 11 están repartidas por toda la geografía española. La única institución que presenta 2 tesis doctorales es la Universidad de Santiago de Compostela y, en ambos casos, se trata de estudiantes latinoamericanos, respondiendo al alto interés, preocupación e investigación sobre la RSU en la región latinoamericana. En cuanto a las fechas de defensa, estas 11 tesis se presentan entre 1 y 2 defensas al año desde 2009 (2) hasta el 2015 (1), fecha límite de nuestra investigación. Esto nos lleva a, por un lado, confirmar el interés sostenido por este tema. No olvidemos que una tesis doctoral implica una inversión de tiempo de, al menos, 4 años, por lo que habrá que esperar aún 4 o 5 años para verificar si existe realmente esta tendencia. Ahora bien, este número de tesis doctorales confirma esta línea de investigación reconocida en el ámbito académico, aunque sin estar ubicada claramente en un área de conocimiento específica. Otro elemento a tener en cuenta es que de esas 11 tesis, 5 han sido defendidas por doctorandos latinoamericanos, lo que induce a pensar que en nuestras universidades aún no existen suficientes redes de investigación consolidadas o con recursos suficientes que promuevan la investigación sobre la RSU.

\subsubsection{Proyectos de investigación}

Por lo que respecta a la investigación, los proyectos con mayor repercusión en este tema, llevados a cabo en el marco de convocatorias públicas financiadas por el Ministerio de Educación, se presentaron y realizaron entre los años 2010 y 2012, fechas que coinciden con el momento álgido en cuanto a número de publicaciones. Hemos acudido a la información pública existente en la web del Ministerio de Educación sobre los Informes de investigaciones financiadas. Estableciendo unos criterios de búsqueda estrictos en torno a la RSU encontramos los siguientes trabajos:

«Evaluación de las políticas de sostenibilidad como facilitadoras para el desarrollo de los campus de excelencia internacional». Esta investigación se llevó a cabo por parte de la CADEP (CRUE) en el marco del programa Estudios y Análisis 
del Ministerio de Educación. Un año más tarde se presentó a la misma convocatoria el proyecto "Integración de la responsabilidad social en los sistemas de garantía interna de calidad: hacia una universidad saludable, sostenible y solidaria", coincidiendo con el proyecto "Guía de responsabilidad social universitaria y discapacidad: RSU-D». También con financiación pública se desarrolló el proyecto de investigación "La Responsabilidad Social como misión en las universidades españolas y su contribución al desarrollo sostenible. Diagnóstico y buenas prácticas».

Ya a nivel europeo, con una significativa presencia de universidades españolas, destacan 2 proyectos "Comparative Research on University Social Responsibility in Europe and Development of a Community Reference Framework» (EU-USR, 20122015) y "Higher Education Institution \& Responsable Research and Innovation", liderado por la Universidad Pompeu Fabra (EU-2015-2018). Aunque sobrepasan el límite geográfico que nos proponemos en este estudio, sí que resulta interesante mencionarlos, ya que evidencian el interés de las universidades europeas por la RSU.

Por otro lado, mencionar proyectos no centrados exclusivamente en la RSU, como es el caso de "Gobierno electrónico y gobernanza en el sistema universitario español» (2010), financiado dentro del Programa de Estudios y Análisis. O el estudio coordinado por Larrán (2014), "Análisis del nivel de implantación de políticas de responsabilidad social en las universidades españolas", impulsado por la Conferencia de Consejos Sociales de las Universidades Públicas Españolas y la Fundación Carolina.

En cuanto a los proyectos I+D+I, financiados por el Ministerio de Economía y Competitividad, no existen registros que recuperen las investigaciones apoyadas, salvo las resoluciones anuales de los proyectos aprobados en el Boletín Oficial del Estado. Aunque estos han sido recogidos, fundamentalmente, a través de las publicaciones, al estar instados a publicar sus resultados, este es un punto que en futuros trabajos debe abordarse.

Todos ellos cuentan con extensos informes y publicaciones que han servido de base para el trabajo en esta área. Se trata de investigaciones restringidas en el ámbito universitario, si ampliamos el foco a la responsabilidad social en el ámbito empresarial, los proyectos son mucho más numerosos.

\subsection{La RSU en la gestión universitaria}

La inclusión de la RSU en el organigrama de la Universidad implica un compromiso importante, ya que al crear un órgano que específicamente se ocupa de la RS se deben facilitar los recursos que faciliten y hagan posible el trabajo. Las formas que puede adoptar son múltiples, desde órganos de gobierno (vicerrectorados) a unidades técnicas como oficinas o comisiones. Se han revisado las webs institucionales de todas las universidades y se recoge que son escasas las universidades que cuentan con un Vicerrectorado que se ocupe explícitamente de la RSU, como, por ejemplo, la Universidad de Cádiz (Vicerrectorado de Responsabilidad Social, 
Extensión Cultural y Servicios Universitarios), o la Universidad Carlos III (Vicerrectorado de Estudiantes, Responsabilidad Social e Igualdad). El número de universidades que cuentan con este tipo de órganos ha crecido en los últimos años, de los 6 vicerrectorados con cita expresa a la RS que recoge Barañano (2011), a los 11 con los que nos encontramos en la actualidad. Esta cifra se eleva a 15 si contemplamos también la referencia explícita a la sostenibilidad o al desarrollo sostenible, como es el caso de la Universidad de Almería (Vicerrectorado de Infraestructuras, Campus y Sostenibilidad). Sin embargo, hemos encontrado que prácticamente todas las universidades públicas cuentan con algún vicerrectorado que incluye, al menos en su denominación, palabras que tienen que ver con la dimensión ambiental, como el Vicerrectorado de Campus, Cooperación y Universidad Saludable de la Universitat de les Illes Balears o alguno de los aspectos relacionados como la cooperación internacional o la igualdad.

Por lo que respecta a las unidades técnicas encontramos, igualmente, una gran heterogeneidad a la hora de nombrarlas y dotarlas de competencias y funciones. En cuanto al número también han experimentado cierto crecimiento, de las 8 con mención expresa a la RS en 2011 (Barañano, 2011), a las 11 que encontramos en la actualidad, número que se eleva cuando hacemos referencia a la sostenibilidad en general o a aspectos concretos de la misma. En este punto debemos hacer una mención especial a las Oficinas Verdes, de Cooperación o de Igualdad. Sin embargo, si tenemos en cuenta la totalidad de universidades existentes en nuestro país todavía su implantación es claramente insuficiente, ya sea de forma global o a partir de acciones concretas.

Igualmente encontramos universidades que depositan las competencias en RSU en un órgano específico sin tener ninguna mención en su nombre, como el Vicerrectorado de Planificación Económica, Convenios y Contratos de la Universidad de Valencia o en la Universidad de Murcia en la que la temática es abordada por la Cátedra de RSC. La conclusión es que no existe una única manera, ni homogénea, de organizar la gestión que realizan las universidades en torno a ella

A la vez, la información que se ofrece sobre el trabajo que se realiza es muy desigual entre las distintas universidades. Mientras que algunas mantienen un espacio dedicado a la RSU con indicación de las actividades que se desarrollan, como es el caso de la Universidad del País Vasco, otras no facilitan esta información. En la misma situación nos encontramos en la difusión y acceso a las Memorias o Informes de RSU, en el caso de aquellas universidades que los elaboran. Hemos detectado que, a día de hoy, son numerosas las universidades que presentan o han presentado un informe de las actividades que desarrollan y que pueden ser enmarcadas en área de la Rs. De las 84 universidades estudiadas, 26 de ellas realizan algún tipo de memoria, bien sea con un formato institucional propio, siguiendo las recomendaciones formuladas por GRI, bien siguiendo el modelo de informe del Pacto Mundial. De ellas, únicamente 3 elaboradas por las universidades privadas, entre ellas la Universidad Europea de Madrid, muy activa a través de su Oficina de RS. Resulta llamativo que ninguna de las universidades «jóvenes» nacidas en este 
siglo haga visible su implicación con la RS, más allá de la realización de alguna jornada o curso.

Por lo que respecta al modelo de las memorias, la gran mayoría se adecúan a las indicaciones del GRI. De los 26 informes recogidos, 3 de ellos se atienen al Informe de Progreso para el Global Compact. Hemos detectado algunos casos de universidades que, sin desarrollar una memoria independiente de RSU, sí incluyen en las memorias académicas las actividades de RSU, como es el caso de la Universidad de Cádiz o de la Universitat Pompeu Fabra. Finalmente, otras universidades mantienen un espacio web con gran cantidad de información sin llegar a publicar memorias, como es la Universidad del País Vasco, ya aludida.

Ahora bien, una vez mencionada la heterogeneidad de estos informes, lo cierto es que esta no siempre se encuentra actualizada, posiblemente, y entre otras causas, debido a la complejidad de la recogida y análisis de datos que exige su elaboración. El grueso de las memorias localizadas pertenece al curso 2012-2013 y únicamente 5 relativas al curso 2013-2014. Es difícil saber en este punto si esto constituye un retraso achacable a la gran cantidad de trabajo que en estos momentos abordan las universidades o bien significa que se está renunciando a la elaboración de estos documentos o, simplemente, una demora de su publicación. Lo cierto es que hay una relación directa entre las universidades que mantienen una unidad encargada de la Rs y aquellas que presentan memorias. También es cierto que estas unidades han visto reducido su personal, por lo que no es de extrañar la priorización de unas acciones con repercusión inmediata en la vida universitaria, frente a otras que, siendo necesarias, puede considerarse que no significan un aporte específico a la mejora de la Universidad.

Grafico 7. NÚmERO TOTAL DE MEMORIAS DisPONIBLES POR AÑO

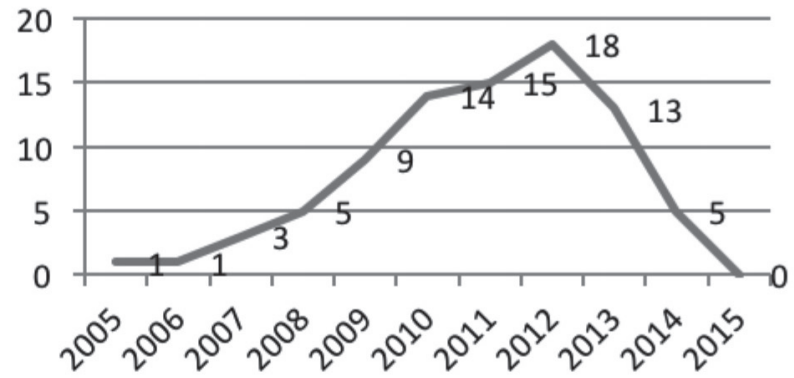

FuENTE: Elaboración propia. 


\subsection{Acciones}

Por lo que respecta a las acciones que se desarrollan bajo el paraguas de la RSU, o que pueden enmarcarse bajo este sentido, son muy variadas. Al menos todas las universidades públicas cuentan con órganos o unidades que trabajan en uno o varios aspectos, cuando no todos ellos y que agrupamos en torno a cuatro ejes:

- Campus, bajo la denominación de verde, sostenible o saludable, engloba medidas para conseguir una gestión acorde con estos principios y una experiencia positiva para los usuarios.

- Equidad, engloba acciones de distinta índole que incluyen el trabajo para eliminar barreras (visibles o invisibles) que afecten a determinados colectivos.

- Medio ambiente, se busca implantar mejoras encaminadas a minimizar los impactos negativos o potenciar los positivos de la actividad universitaria en el entorno natural y social.

- Cooperación, se pretende establecer lazos de ayuda con comunidades necesitadas en un contexto próximo o a nivel internacional y, en estos últimos años, acciones de aprendizaje servicio.

La tipología de estas es muy variada y van desde diseños puntuales hasta programas que buscan un alto impacto a través de la interrelación de todos los ejes. Sin embargo, echamos en falta un eje fundamental, presente en muy pocas universidades, si tenemos en cuenta que estamos analizando actividades de instituciones universitarias. Se trata de la sostenibilización curricular, es decir, la inclusión de la temática de la sostenibilidad en todos los programas formativos, ya indicado por la CRUE (2005) incidiendo en la inclusión de los contenidos transversales básicos en sostenibilidad en todas las titulaciones. En esta cuestión "no se trata tanto de "ampliar" contenidos de aprendizaje cuanto de "repensar", "integrar" y "transformar" la docencia orientándola hacia la sostenibilidad" (Murga-Menoyo, 2015, 77). Si entendemos que la Universidad genera el mayor impacto a través de la formación de estudiantes que son y serán ciudadanos y futuros profesionales, entendemos que la sostenibilización curricular es un elemento fundamental de RSU.

\section{RSU, ¿INTERESA A LA UNIVERSIDAD?}

Una de las primeras conclusiones a la que llegamos es que la RSU no es un concepto que refleje una moda, más o menos pasajera, ni una acción que pueda sumarse sin más a la dinámica de una institución universitaria. Tampoco se trata de un contenido a incluir en un programa o asignatura. Tal como se desprende del contenido y dinámica de la RSC y de la RSE, la Universidad como organización que es, con unas funciones determinadas y una misión que cumplir, debe ser consciente $-\mathrm{y}$ de hecho lo es- de su responsabilidad ante la sociedad. Ahora esto va a suponer un cambio en el modelo de Universidad, ya que afecta a todos los ámbitos específicos de actuación de estas instituciones. Docencia, investigación, 
gestión y participación social deben replantearse, ya que cada una de estas debe estar diseñada para responder a las necesidades y demandas sociales. Y debe ser capaz de rendir cuentas aportando resultados que apoyen el desarrollo de la sociedad. O, como lo plantea Londoño $(2013$, 138), ser capaz de responder a las siguientes cuestiones:

- Campus responsable: ¿Cómo debe la institución de educación superior promover un comportamiento organizacional responsable basado en prácticas éticas, democráticas y ambientalmente sostenibles?

- Formación profesional y ciudadana: ¿Cómo debe la institución de educación superior organizarse para formar ciudadanos comprometidos con el desarrollo de la sociedad?

- Gestión social del conocimiento: ¿Qué conocimientos debe producir la Institución de Educación Superior, y con quiénes y cómo debe difundirlos para permitir su apropiación social y atender las carencias cognitivas que afectan a la comunidad?

- Participación social: ¿Cómo puede la institución de educación superior interactuar eficazmente con la sociedad para promover un desarrollo más humano y sostenible?

Resulta significativo que la RSU interesa, pero en áreas de conocimiento determinados. Destacan las titulaciones de Ciencias Económicas y Empresariales, las de Ciencias de la Salud, Ciencias Ambientales, Ingenierías y, últimamente, Turismo. En cambio en otras titulaciones las aportaciones son puntuales, como es el caso de Educación, o simplemente está ausente. Es cierto que en el área de Teoría de la Educación interesan determinadas acciones englobadas en la RSU, como son la identidad social de la institución universitaria o la Universidad como comunidad ética, punto que no hemos abordado en este trabajo, ya que desborda su objetivo. En cuanto a oferta formativa en grado y postgrado, cátedras, grupos de investigación destacan de nuevo las Facultades de Económicas y Empresariales. Su actividad es sumamente dinámica, aunque los resultados obtenidos no incidan en la mejora de la gestión de estas instituciones. De alguna manera, deberíamos recuperar este concepto y su implicación para abordar una verdadera modernización de la Universidad (European Commission, 2014).

Utilizando el enfoque de Larrán y Andrades (2013a), también diferenciamos frenos y aceleradores en la incorporación de la RSU en nuestras instituciones. Frenos, coincidiendo con estos autores, en la falta de tiempo, de formación, de recursos humanos, el escaso interés, compromiso y conciencia de los empleados y/o estudiantes -los grupos de interés-, la falta de cultura hacia la responsabilidad social de las organizaciones o de indicadores de rendimiento que garanticen su evaluación, la complejidad de la estructura organizativa de estas instituciones tremendamente jerárquica o la ausencia de liderazgo entre los gestores universitarios. Aunque, como se ha expuesto, en gran parte de las universidades está incluida la RSU de una u otra forma, esta queda diluida ya sea porque se centra en acciones 
aisladas, o muy localizadas, como es el caso de las actividades en torno a medio ambiente o equidad. Relevantes, sin duda, pero que reducen significativamente este concepto. Por otro lado, uno de los grandes inconvenientes para su incorporación en la gestión universitaria es la ausencia de la RSU como concepto transversal en todas las titulaciones y, especialmente, la falta de formación de los propios docentes en RS, con todo lo que ello implica.

En cuanto a los aceleradores, la adopción de prácticas de responsabilidad social se traduciría en un mayor acercamiento a la sociedad, por ejemplo, mejorando la formación de los egresados, lo que se traduciría en una mejor integración en su puesto de trabajo. Esto conlleva también una mejora de la imagen y la reputación vía divulgación de información social y ambiental, de la competitividad, del liderazgo de las universidades, además de recuperar su carácter innovador, ya que «[...] donde ser efectivo pasa por ser pionero y ello comprende tener misiones y responsabilidades apropiadas» (Larrán y Andrades, 2013a, 247).

En suma, comprender la RSU como un nuevo modo de entender la Universidad, de acercarla a la sociedad, de responder a la misión de estas instituciones: la formación y la investigación, dirigidas al desarrollo del entorno, próximo y lejano, en la que está enclavada. "Sobre estas directrices, la RSU debe configurarse como un modelo de dirección y gestión de las universidades basadas en una serie de principios sociales, éticos y/o medioambientales, los cuales deben impregnar cada una de las principales funciones de las universidades, todo ello desde una idea centrada en las externalidades que produce la actividad de las universidades en la sociedad» (Larrán y Andrades, 2015, 107). En suma, la Universidad no puede permanecer ajena a la realidad en la que vive, sino que debe ser motor de desarrollo y de cohesión social. De ahí que la RSU deba interesar a la Universidad y deba ser objeto de futuras investigaciones.

\section{REFERENCIAS BIBLIOGRÁFICAS}

BARAÑANO, M. (2012) La responsabilidad social como misión en las universidades españolas y su contribución al desarrollo sostenible. Diagnóstico y buenas prácticas. Consultado el 23 de septiembre de 2014. http://138.4.83.162/mec/ayudas/repositorio/2012113021 3510INFORME_RSU_2.pdf.

Barrera, J. J. (2008) La administración pública y la RSE, en Granda Revilla, G. y CAMisón, C. (dirs.) El modelo de empresa del siglo XXI: hacia una estrategia. Madrid, Ediciones Cinca/FORETICA, 74-78.

Benavides, J.; Fernández Fernández, J. L. y Urtiaga de Vivar, A. (2012) Glosario sobre la responsabilidad social para la investigación y el debate terminológico. Madrid, Universidad Pontificia de Comillas.

Bestraten, M. y PÀmias, O. (2014) Responsabilidad social de las empresas. Modelo GRi G-4. Consultado el 23 de abril de 2015. http://goo.gl/3iabzo.

CASTILLO, I. (2010) Una aproximación al estado de la RSE en la enseñanza en España. Club de Excelencia en Sostenibilidad. Consultado el 28 de septiembre de 2014. http://goo. $\mathrm{gl} / \mathrm{h} 91 \mathrm{k} 1 \mathrm{~L}$. 
Cátedra JaVIer Benjumea. (2009) Observatorio académico de la RSE y la ética empresarial en la educación superior en España. Consultado el 27 de febrero de 2015. http://goo.gl/ e3jXdl.

Cea Moure, R. (2010) La responsabilidad social corporativa en las entidades bancarias de la Unión Europea. Análisis empírico y propuesta de modelo normalizado. [Tesis doctoral]. Madrid, Universidad Autónoma de Madrid.

CERSE (2014) Estrategia 2014-2020 para empresas, administraciones públicas y el resto de organizaciones para avanzar hacia una sociedad y una economía más competitiva, productiva, sostenible e integradora. Ministerio de Empleo y Seguridad Social. Consultado el 10 de noviembre de 2014. http://goo.gl/eCYjKB.

Comisión de las Comunidades Europeas (2006) Comunicación de la Comisión al Consejo y al Parlamento Europeo cumplir la agenda de modernización para las universidades: educación, investigación e innovación. com 208 Final. Consultado el 10 de septiembre de 2014. http://goo.gl/5Cd9wK.

Comisión de las Comunidades Europeas (2011) Apoyar el crecimiento y el empleo -una agenda para la modernización de los sistemas de educación superior en Europa-. СОм 567 Final. Consultado el 10 de septiembre de 2014. http://goo.gl/so7nqJ.

Comisión TÉCNiCA de la Estrategia Universidad 2015 (2011) La responsabilidad social de la universidad y el desarrollo sostenible. Madrid, Ministerio de Educación.

CRUE (2005) Directrices para la sostenibilización curricular. Documento del grupo de trabajo de Calidad Ambiental y Desarrollo Sostenible. Consultado el 16 de enero de 2015. https://goo.gl/eQyqBo.

Cuesta, M. De la; Cruz, C. De la y Rodríguez, J. M. (2010) Responsabilidad social universitaria. La Coruña, Netbiblo.

Egido, I.; Fernandez díaz, M. J. y Galán, A. (2014) la dimensión social del proceso de Bolonia: apoyos y servicios para grupos de estudiantes poco representados en las universidades españolas. Educación XX1, 17 (2), 57-81. Doi: dx.doi.org/10.5944/educxx1.17.2.11479.

European Commission (2014) New modes of learning and teaching in Higher Education. Luxembourg, Publications Office of the European Union.

EU USR (2015) Comparative Research on University Social Responsibility in Europe and Development of a Community Reference Framework (EU-USR). Consultado el 16 de enero de 2015. http://www.eu-usr.eu/.

GaETe QuezadA, R. (2011) La responsabilidad social universitaria como desafío para la gestión estratégica de la Educación Superior: el caso de España. Revista de Educación, $355,109-133$.

Galán Amador, M. (2013) Estudios Exploratorios o Formulativos. Metodología de la Investigación. [Blog], 8 de enero. Consultado el 16 de enero de 2015. http://goo.gl/ayQQcX.

García Benau, M. A. (2014) Responsabilidad Social Universitaria y desarrollo sostenible. Madrid, Fundación Europea Sociedad y Educación.

Guedez, V. (comp.) (2010) Responsabilidad social empresarial. Visiones complementarias. Caracas, Venamcham. Consultado el 16 de enero de 2015. http://goo.gl/fNyxci.

Larrán, M. (coord.) (2014) Análisis del nivel de implantación de políticas de responsabilidad social en las universidades españolas. Consultado el 10 de diciembre de 2014. http:// goo.gl/vxgqGc.

LARRÁN, M. y ANDRADES, F. J. (2013a) Frenos y aceleradores para la implantación de la responsabilidad social en las universidades españolas. Prisma Social. Revista de Investigación Social, 10, 233-270. 
LARRÁN, M. y ANDrades, F. J. (2013b) Presencia de la responsabilidad social en las titulaciones de grado de las universidades españolas. Granada, Conferencia de Consejos Sociales.

LARRÁn, M. y ANDrades, F. J. (2015) Análisis de la responsabilidad social universitaria desde diferentes enfoques teóricos. Revista Iberoamericana de Educación Superior, 6, 91-107.

LONDOÑO, I. C. (2013) Responsabilidad Social Universitaria: una Estrategia de Gestión para la Educación Superior. Sinapsis, 5 (5), 137-151.

Lozano, J. M. (2007) Promoción pública de la responsabilidad social empresarial. Ekonomiaz, 65 (2), 108-127.

Ministerio de Ciencia e InNOvación (s/f) Estrategia Universidad 2015. Universidades para el progreso, el bienestar y la competitividad. Consultado el 16 de septiembre de 2014. http://goo.gl/Fd36rp.

Ministerio de EdUCACIÓN (2011) Estrategia Universidad 2015. Contribución de las universidades al progreso socioeconómico español 2010-2015. Consultado el 24 de octubre de 2014. https://goo.gl/fwmSYa.

Ministerio De EDUCACIÓN (s/f) Plan de acción para el apoyo y la modernización de la universidad pública española en el marco de la Estrategia Universidad 2015. Consultado el 16 de enero de 2015. http://goo.gl/ibV1jJ.

MiNISTERIO DE EDUCACIÓN (2011) La responsabilidad social de la universidad y el desarrollo sostenible. Consultado el 16 de enero de 2015. https://goo.gl/4tXDAK.

Ministerio de EMPLEO y SEGURIDAd SOCIAL (2015) Estrategia 2014-2020 para empresas, administraciones públicas y el resto de organizaciones para avanzar hacia una sociedad y una economía más competitiva, productiva, sostenible e integradora. Madrid, Ministerio de Empleo y Seguridad Social.

Murga-Menoyo, M. A. (2015) Competencias para el desarrollo sostenible: las capacidades, actitudes y valores meta de la educación en el marco de la Agenda global post-2015. Foro de Educación, 13 (19), 55-83. Doi: http://dx.doi.org/10.14516/fde.2015.013.019.004.

Naval, C. y Ruiz-Corbella, M. (2012) Aproximación a la Responsabilidad Social. Universitaria: la respuesta de la universidad a la sociedad. Bordón. Revista de Pedagogía, 64 (3), 103-116.

OlCESE, A. (coord.) (2013) Informe sobre la responsabilidad social de la empresa en España. Una propuesta para Europa. Consultado el 24 de febrero de 2015. http://goo.gl/ ovYv05.

OIT (s/f) La OIT y la Responsabilidad Social de la empresa (RSE). Helpdesk de la OIT, 1. Consultado el 16 de marzo de 2016. http://goo.gl/gOGmd6.

Pacenza, M. I. y Silva Peralta, Y. F. (2013) Análisis bibliométrico sobre responsabilidad social universitaria. Psychology, Society, E Education, 5 (2), 125-138.

Pinillos, A. A. y Fernández, J. L. (2011) De la RSC a la sostenibilidad corporativa: una evolución necesaria para la creación de valor. Harvard Deusto Business Review, diciembre, $5-21$.

Puentes Poyatos, R. y Mozas Moral, A. (2010) La responsabilidad social corporativa y su paralelismo con las sociedades cooperativas. Revesco. Revista de Estudios Cooperativos, $103,75-100$.

Rubio, M. J. (2006) Conferencia inaugural, en Granda, G. (dir.) Gestión y comunicación de la responsabilidad social empresarial: claves para un desarrollo competitivo y sostenible. Madrid, Ediciones Cinca/FORETICA, 9-12.

Salmi, J. (2009) The Growing Accountability Agenda in Tertiary Education: Progress or Mixed Blessing? Washington, D. C. World Bank. Consultado el 23 de noviembre de 2014. https://goo.gl/BkEkRt. 
Sursock, A. (2015) Trends 2015: Learning and Teaching in European Universities. Brussells: EUA.

UNESCO (2009) Conferencia Mundial sobre Educación Superior. París, unESCO.

VÁzquez, O. (2012) Crisis: consecuencia de un modelo de desarrollo insostenible. Dossieres EsF, 4, 6-9.

VAlLaeys, F. (2008) Responsabilidad Social Universitaria: una nueva filosofía de gestión ética e inteligente para las universidades. Revista Educación Superior y Sociedad, 13 (2), 191-219.

Vallaeys, F. (2009) Responsabilidad social universitaria. Manual de primeros pasos. México, MacGraw-Hill.

VAlLAeYS, F. (2014) La responsabilidad social universitaria: un nuevo modelo universitario contra la mercantilización. Revista. Iberoamericana de Educación Superior, 5 (12), $105-117$. 